\title{
A comparison of optimization theories for energy conservation in heat exchanger groups
}

\author{
CHEN Qun ${ }^{1,2 *}$, WU Jing ${ }^{3}$, WANG MoRan ${ }^{4}$, PAN Ning $^{2}$ \& GUO ZengYuan ${ }^{1}$ \\ ${ }^{1}$ Key Laboratory for Thermal Science and Power Engineering of Ministry of Education, Department of Engineering Mechanics, Tsinghua \\ University, Beijing 100084, China; \\ ${ }^{2}$ Department of Biological and Agricultural Engineering, University of California, Davis CA 95616, USA; \\ ${ }^{3}$ College of Energy and Power Engineering, Nanjing University of Aeronautics and Astronautics, Nanjing 210016, China; \\ ${ }^{4}$ Earth and Environmental Sciences Division, Los Alamos National Laboratory, Los Alamos NM 87545, USA
}

Received July 27, 2010; accepted August 22, 2010

\begin{abstract}
In general, thermal processes can be classified into two categories: heat-work conversion processes and heat transfer processes. Correspondingly, the optimization of thermal processes has to have two different criteria: the well known entropy generation minimization method and the recently proposed entransy dissipation maximization method. This study analyzes the thermal issues in a heat exchanger group, and optimizes the unit arrangements under different constraints based on a suitable optimization criterion. The result indicates that the principle of minimum entropy generation rate is valid for optimizing heat exchangers in a thermodynamic cycle with given boundary temperatures. In contrast, the entransy dissipation maximization is more suitable in heat exchanger optimizations involving only heat transfer processes. Furthermore, the entropy generation rate induced by dumping used streams into ambient surroundings has to be taken into account, except for that originating from the hot and cold-ends of heat exchangers, when using the entropy generation minimization to optimize heat exchangers undergoing a thermodynamic cycle.
\end{abstract}

heat exchangers, optimization criterion, entransy dissipation maximization, entropy generation minimization

Citation: $\quad$ Chen Q, Wu J, Wang M R, et al. A comparison of optimization theories for energy conservation in heat exchanger groups. Chinese Sci Bull, 2011, 56: 449-454, doi: 10.1007/s11434-010-4297-7

Heat exchangers, one of the most important devices in thermal engineering, are being used in more than $80 \%$ of energy utilization systems. Improving their effectiveness has often been regarded as the key issue in energy conservation. Consequentially, thermal engineers have developed a large number of passive and active technologies to enhance thermal performance by adding extended or rough surfaces and various inserts to enlarge the exchange surfaces or by introducing surfaces or fluid vibrations and external electric or magnetic field to expedite the process [1-3]. Although all of these ideas have been more or less successful in reducing energy consumption, the fundamental physics involved is still not clear. One issue is the relationship between heat exchanger effectiveness and heat

*Corresponding author (email: chenqun@tsinghua.edu.cn) transfer irreversibility, noting that heat transfer is an irreversible process [4]. The crucial problem is in understanding why heat exchangers with different flow arrangements lead to diverse heat transfer performances under the same given conditions.

Using the entropy generation as a measure of irreversibility for any irreversible process, Bejan [5,6] introduced the concept of irreversibility as being due to finite temperature difference as well as fluid friction in heat transfer processes and optimized the regenerative heat exchanger for a Brayton cycle heat engine based on the criterion of minimum entropy generation. Thereafter several researchers, e.g. Poulikakos [7], Grazzini [8], Sekulic [9], Sara [10], Johannessen [11], Balkan [12], Ko [13] and Erek [14] analyzed the influences of geometries, flow arrangements and operational parameters on entropy generation for various 
heat exchangers, and then optimized them subject to minimal entropy generation. However, Bejan found that the effectiveness for counter-flow heat exchangers does not vary monotonically with entropy generation, and called this the "entropy generation paradox". An attempt was made by Hesselgreaves [15] to reconcile the problem by non-dimensionalizing the entropy generation rate, whereas Shah et al. [16] pointed out that heat exchanger effectiveness can be at either maximum or minimum or in between at the minimum entropy generation operating point, all depending on the flow arrangement of the two fluids, that is, the entropy generation minimum is not applicable to all heat exchanger analysis.

Recently, a new physical quantity, $(U T) / 2$, termed as the entransy, which describes the heat transfer ability of a system, was introduced by Guo et al. [17]. The entransy dissipation rate was identified and used to measure the irreversibility of a heat transfer process. Furthermore, Guo et al. [17] proposed an alternative criterion for heat transfer optimization: the entransy dissipation extrema correspond to the optimal performance of heat transfer processes not involving a thermodynamic cycle. In [18], the concept of entransy was originally referred to as the heat transfer potential capacity, and this new theory has been applied in studying and optimizing heat conduction $[17,19,20]$, convective heat transfer [21-24], thermal radiation [25] and the heat transfer performance in a single heat exchanger [26-28]. Moreover, some novel heat transfer enhancement technologies have been developed, e.g. the alternating elliptical axis tubes [29] and the discrete doubled inclined rib tubes [23].

In summary, in addition to the entropy criterion by Bejan $[5,30]$, called the thermodynamic optimization, Guo et al. [17] has proposed the concept of entransy and a related objective function referred to here as the heat transfer optimization. The objective of this paper is to examine the physical essentials of those two different criteria, their differences, and more importantly their applicability to practical heat exchanger groups.

\section{Irreversibility of heat transfer processes in a heat exchanger group}

Figure 1 shows the schematic diagram of a heat exchanger group with a fluid distributor assigning the incoming hot fluid into two (left and right side) heat exchangers. The hot fluid with temperature $T_{\mathrm{in}}$ and heat capacity rate $C_{\mathrm{h}}=\dot{m}_{\mathrm{h}} c_{\mathrm{p}}$ flows through the distributor into the heat exchangers, with heat capacity rates $C_{\mathrm{h} 1}$ and $C_{\mathrm{h} 2}$ respectively, on each side. The wall temperatures $T_{\mathrm{h} 1}$ and $T_{\mathrm{h} 2}$ of the two exchangers are assumed constant, and the corresponding outlet temperatures of the fluid are $T_{\text {out1 }}$ and $T_{\text {out2 }}$. Thus, we have

$$
\dot{Q}_{\mathrm{h} 1}=C_{\mathrm{h} 1}\left(T_{\mathrm{in}}-T_{\text {out } 1}\right)
$$

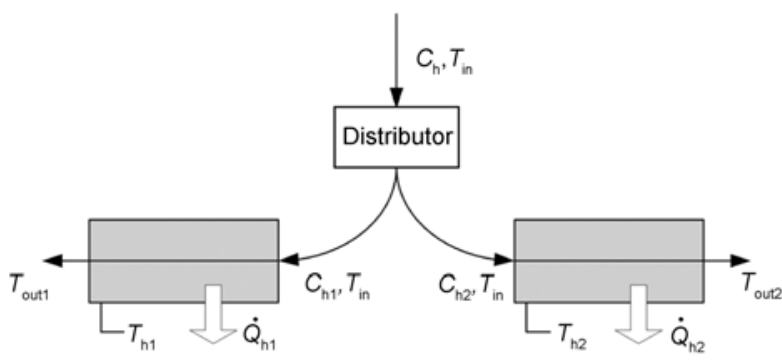

Figure 1 Schematic sketch of a heat exchanger group.

and

$$
\dot{Q}_{\mathrm{h} 2}=C_{\mathrm{h} 2}\left(T_{\text {in }}-T_{\text {out } 2}\right) \text {, }
$$

where $\dot{Q}_{\mathrm{h} 1}$ and $\dot{Q}_{\mathrm{h} 2}$ are the heat flow rates in the two exchangers.

During the heat transfer process, the total thermal energy is conserved, i.e. the decrease in thermal energy of the hot fluid should be equal to the heat transferred out through the two exchangers. However, the entropy is not conserved in the process. Based on the second law of thermodynamics, Bejan [30] deduced the entropy generation rate (EGR) $\dot{S}$ in a heat exchanger to measure the irreversibility induced by heat transfer:

$$
\dot{S}=C \ln \frac{T_{\text {out }}}{T_{\text {in }}}+\frac{\dot{Q}}{T_{\mathrm{w}}} .
$$

Thus, the EGR during the heat transfer process in the heat exchanger group is

$$
\dot{S}_{\mathrm{g} 1}=\left(C_{\mathrm{h} 1} \ln \frac{T_{\mathrm{out} 1}}{T_{\mathrm{in}}}+\frac{\dot{Q}_{\mathrm{h} 1}}{T_{\mathrm{h} 1}}\right)+\left(C_{\mathrm{h} 2} \ln \frac{T_{\text {out } 2}}{T_{\mathrm{in}}}+\frac{\dot{Q}_{\mathrm{h} 2}}{T_{\mathrm{h} 2}}\right) .
$$

In parallel, by analogy between heat and electric conduction, a physical quantity, $E_{\mathrm{h}}$, termed entransy, was introduced by Guo et al. [17] to describe the heat transfer ability of an object

$$
E_{\mathrm{h}}=\frac{1}{2} m c_{\mathrm{p}} T^{2}
$$

where $m, c_{\mathrm{p}}$ and $T$ are the mass, the constant pressure specific heat, and the temperature of the object, respectively. Meanwhile, the total entransy flow rate accompanying the mass flow rate at the inlet is

$$
\dot{E}_{\mathrm{hin}}=\frac{1}{2}\left(C_{\mathrm{h} 1}+C_{\mathrm{h} 2}\right) T_{\mathrm{in}}^{2},
$$

with the entransy flow rates at the left and right outlets being

$$
\dot{E}_{\text {hout } 1}=\frac{1}{2} C_{\mathrm{h} 1} T_{\text {out } 1}^{2}
$$

and 


$$
\dot{E}_{\text {hout } 2}=\frac{1}{2} C_{\mathrm{h} 2} T_{\text {out } 2}^{2} \text {. }
$$

In addition, the entransy flow rates, accompanying the heat flow rates out of the two exchangers through wall boundary are

$$
\dot{E}_{\mathrm{hw} 1}=\dot{Q}_{\mathrm{h} 1} T_{\mathrm{h} 1}
$$

and

$$
\dot{E}_{\mathrm{hw} 2}=\dot{Q}_{\mathrm{h} 2} T_{\mathrm{h} 2} \text {. }
$$

By subtracting eqs. (7)-(10) from eq. (6), we have the entransy dissipation rate $\dot{\Phi}_{h}$ in the heat exchanger group

$$
\begin{aligned}
\dot{\Phi}_{\mathrm{h}}= & \frac{1}{2}\left(C_{\mathrm{h} 1}+C_{\mathrm{h} 2}\right) T_{\mathrm{in}}^{2} \\
& -\left(\frac{1}{2} C_{\mathrm{h} 1} T_{\text {out } 1}^{2}+\frac{1}{2} C_{\mathrm{h} 2} T_{\text {out } 2}^{2}+\dot{Q}_{\mathrm{h} 1} T_{\mathrm{h} 1}+\dot{Q}_{\mathrm{h} 2} T_{\mathrm{h} 2}\right) .
\end{aligned}
$$

Guo et al. [17] considered that this entransy dissipation rate, rather than the entropy generation rate, should be used to measure the heat transfer induced irreversibility, if the transferred heat is applied to heat/cool an object rather than to do work.

\section{Optimization of the heat exchanger group for heating/cooling}

Consider again the heat exchanger group that is sketched in Figure 1, which is not involved in any thermodynamic cycles. The optimization objective is to maximize the heat flow rate. Because the thermal conductance inventories of the exchangers are commodities in short supply, it makes sense to consider as a constraint the total thermal conductance inventory $U A[6]$

$$
U A=(U A)_{1}+(U A)_{2}=\text { const }
$$

or, in terms of the thermal conductance allocation ratio $x$,

$$
(U A)_{1}=x U A, \quad(U A)_{2}=(1-x) U A,
$$

where $(U A)_{1}$ and $(U A)_{2}$ are the thermal conductances for the left and right exchangers, respectively, $U$ is the heat transfer coefficient, and $A$ is the heat transfer area.

Merging eqs. (1) and (2) with the heat transfer equation gives the heat flow rates in each exchanger as

$$
\dot{Q}_{\mathrm{h} 1}=C_{\mathrm{h} 1}\left(T_{\mathrm{in}}-T_{\mathrm{h} 1}\right)\left(1-\mathrm{e}^{\frac{-(U A)_{1}}{C_{\mathrm{h} 1}}}\right)
$$

and

$$
\dot{Q}_{\mathrm{h} 2}=C_{\mathrm{h} 2}\left(T_{\mathrm{in}}-T_{\mathrm{h} 2}\right)\left(1-\mathrm{e}^{\frac{-(U A)_{2}}{C_{\mathrm{h} 2}}}\right) \text {. }
$$

Combining eqs. (13)-(15) yields the total heat flow rate

$$
\begin{aligned}
\dot{Q}_{\mathrm{h}}= & \dot{Q}_{\mathrm{h} 1}+\dot{Q}_{\mathrm{h} 2}=C_{\mathrm{h} 1}\left(T_{\mathrm{in}}-T_{\mathrm{h} 1}\right)\left(1-\mathrm{e}^{\left.\frac{-x U A}{C_{\mathrm{h} 1}}\right)}\right. \\
& +C_{\mathrm{h} 2}\left(T_{\mathrm{in}}-T_{\mathrm{h} 2}\right)\left(1-\mathrm{e}^{\frac{-(1-x) U A}{C_{\mathrm{h} 2}}}\right) .
\end{aligned}
$$

By substituting eqs. (14)-(16) into the entropy generation equation, eq. (4), and the entransy dissipation equation, eq. (11), respectively, we have

$$
\begin{aligned}
\dot{S}_{\mathrm{g} 1}= & C_{\mathrm{h} 1} \ln \frac{T_{\mathrm{h} 1}+\left(T_{\mathrm{in}}-T_{\mathrm{h} 1}\right) \mathrm{e}^{\frac{-x U A}{C_{\mathrm{h} 1}}}}{T_{\mathrm{in}}} \\
+ & \frac{C_{\mathrm{h} 1}\left(T_{\mathrm{in}}-T_{\mathrm{h} 1}\right)\left(1-\mathrm{e}^{\frac{-x U A}{C_{\mathrm{h} 1}}}\right)}{T_{\mathrm{h} 1}} \\
+ & C_{\mathrm{h} 2} \ln \frac{T_{\mathrm{h} 2}+\left(T_{\mathrm{in}}-T_{\mathrm{h} 2}\right) \mathrm{e}^{\frac{-(1-x) U A}{C_{\mathrm{h} 2}}}}{T_{\mathrm{in}}} \\
+ & \frac{C_{\mathrm{h} 2}\left(T_{\mathrm{in}}-T_{\mathrm{h} 2}\right)\left(1-\mathrm{e}^{\frac{-(1-x) U A}{C_{\mathrm{h} 2}}}\right)}{T_{\mathrm{h} 2}}
\end{aligned}
$$

and

$$
\dot{\Phi}_{\mathrm{h}}=\frac{1}{2}\left(\begin{array}{l}
C_{\mathrm{h} 1}\left(T_{\mathrm{in}}-T_{\mathrm{h} 1}\right)^{2}\left(1-\mathrm{e}^{\frac{-2 x U A}{C_{\mathrm{h} 1}}}\right) \\
+C_{\mathrm{h} 2}\left(T_{\mathrm{in}}-T_{\mathrm{h} 2}\right)^{2}\left(1-\mathrm{e}^{\frac{-2(x-1) U A}{C_{\mathrm{h} 2}}}\right)
\end{array}\right) .
$$

If the following parameters: (1) the inlet fluid temperature, $T_{\mathrm{in}}$, (2) the wall temperatures, $T_{\mathrm{h} 1}$ and $T_{\mathrm{h} 2}$, and (3) the heat capacity rates, $C_{\mathrm{h} 1}$ and $C_{\mathrm{h} 2}$ in eqs. (15)-(17), are given, all the rates of total heat flow, entropy generation and entransy dissipation are determined through the thermal conductance allocation ratio $x$.

As an example, at $U A=2 \mathrm{~W} / \mathrm{K}, C_{\mathrm{h} 1}=2 \mathrm{~W} / \mathrm{K}, C_{\mathrm{h} 2}=1 \mathrm{~W} / \mathrm{K}$, $T_{\mathrm{in}}=900 \mathrm{~K}, T_{\mathrm{h} 1}=800 \mathrm{~K}$ and $T_{\mathrm{h} 2}=600 \mathrm{~K}$, the rates of total heat flow, entransy dissipation and entropy generation as functions of the thermal conductance allocation ratio, $x$, are calculated and given in Figure 2. The vertical coordinates are normalized by their individual maximum values for ease in comparison. It can be readily found in Figure 2 that the entransy dissipation maximum corresponds to the maximum total heat flow rate at $x=0.3$, while the entropy generation rate reaches its maximum at $x=0.2$. Clearly, the maximum entransy dissipation rate, rather than the minimum entropy generation rate, should be used as a criterion to optimize the thermal performance of heat exchangers, with the purpose 


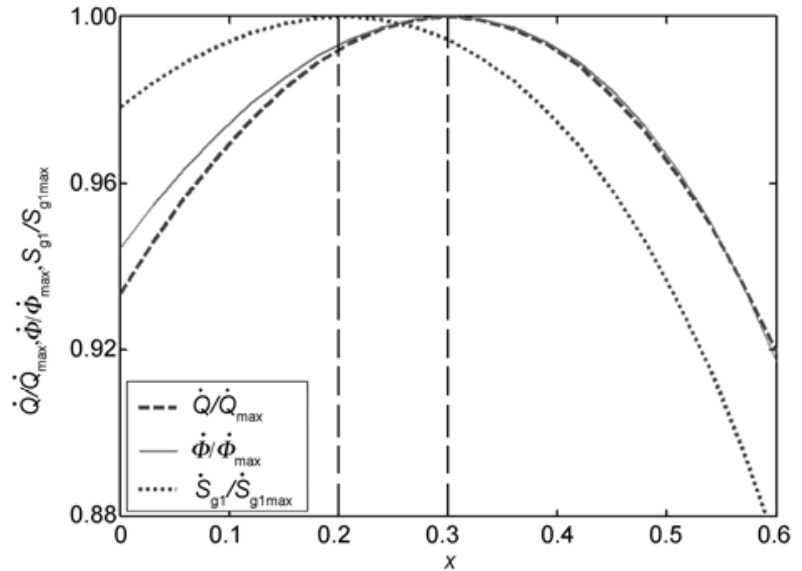

Figure 2 The rate of total heat flow, entransy dissipation and entropy generation versus the thermal conductance allocation ratio.

of object heating or cooling.

\section{Optimization of heat exchanger group for heat-to-work conversion}

When the heat exchanger is a component of a thermodynamic cycle, the optimization objective is usually to maximize the total power output of the cycle. Consider two thermodynamic cycles with each of the aforementioned two heat exchangers being a part of system, as shown in Figure 3. All the parameters of the exchangers are the same as those shown in Figure 1. These two thermodynamic cycles with the same cold-end temperature as the ambient temperature are assumed reversible in order to simplify the analysis.

Based on the second law of thermodynamics, the total power output of the cycles $\dot{W}$ is

$$
\dot{W}=\dot{W}_{1}+\dot{W}_{2}=Q_{\mathrm{h} 1} \frac{T_{\mathrm{h} 1}-T_{\mathrm{c} 1}}{T_{\mathrm{h} 1}}+Q_{\mathrm{h} 2} \frac{T_{\mathrm{h} 2}-T_{\mathrm{c} 2}}{T_{\mathrm{h} 2}},
$$

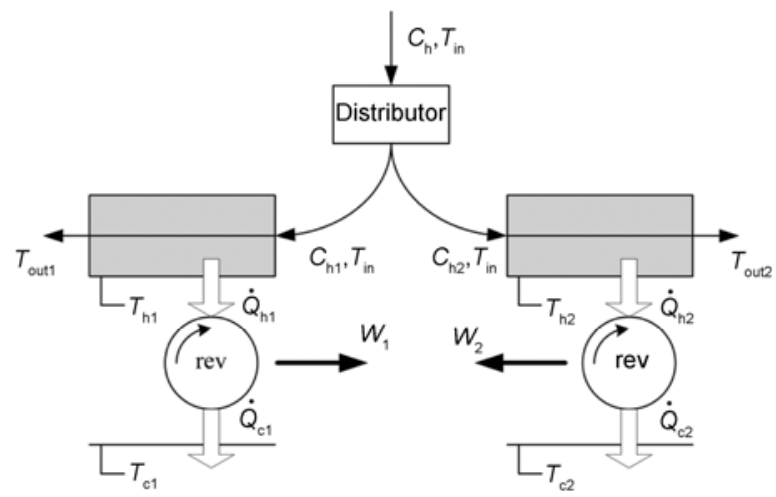

Figure 3 Sketch of two thermodynamic cycles with a heat exchanger group. where $T_{\mathrm{c} 1}$ and $T_{\mathrm{c} 2}$ are the respective cold-end temperatures of the left and right cycles.

Substituting eqs. (11), (12) and (14) into eq. (19) gives the relation between the total power output of the cycles and the thermal conductance allocation ratio $x$,

$$
\begin{aligned}
\dot{W}= & C_{\mathrm{h} 1}\left(T_{\mathrm{in}}-T_{\mathrm{h} 1}\right)\left(1-\mathrm{e}^{\frac{-x(U A)}{C_{\mathrm{h} 1}}}\right) \frac{T_{\mathrm{h} 1}-T_{\mathrm{c} 1}}{T_{\mathrm{h} 1}} \\
& +C_{\mathrm{h} 2}\left(T_{\mathrm{in}}-T_{\mathrm{h} 2}\right)\left(1-\mathrm{e}^{\frac{(x-1)(U A)}{C_{\mathrm{h} 2}}}\right) \frac{T_{\mathrm{h} 2}-T_{\mathrm{c} 2}}{T_{\mathrm{h} 2}} .
\end{aligned}
$$

Setting $T_{\mathrm{c} 1}=T_{\mathrm{c} 2}=300 \mathrm{~K}$, three rate-allocation ratio curves, again normalized by their individual maximum values, are illustrated in Figure 4. At $x=0.30$, both the heat flow rate and the entransy dissipation rate reach their respective maxima, simultaneously, yet do not correspond to the maximum total power output $\dot{W}$ of the cycles. Therefore, it can be concluded that the criterion of entransy dissipation maximum is not applicable in optimizing a heat exchanger group involved in a thermodynamic cycle. Now let us have a look whether the minimum entropy generation is a better option.

Bejan [6] indicated in the discussion on power plant optimization that the entropy generation rate $\dot{S}_{\mathrm{g} 2}$, associated dumping the used streams into the ambient surroundings, must be taken into account except for the entropy generation rate in the heat exchangers. Thus, we have the total entropy generation rate in the system, depicted in Figure 3, as follows:

$$
\begin{aligned}
\dot{S}_{\mathrm{gh}}=\underbrace{\left(C_{\mathrm{h} 1} \ln \frac{T_{\text {out } 1}}{T_{\mathrm{in}}}+\frac{\dot{Q}_{\mathrm{h} 1}}{T_{\mathrm{h} 1}}+C_{\mathrm{h} 2} \ln \frac{T_{\text {out } 2}}{T_{\mathrm{in}}}+\frac{\dot{Q}_{\mathrm{h} 2}}{T_{\mathrm{h} 2}}\right)}_{\dot{S}_{g 1}} \\
+\underbrace{\left(C_{\mathrm{h} 1} \ln \frac{T_{0}}{T_{\text {out } 1}}+\frac{\dot{Q}_{\mathrm{e} 1}}{T_{0}}+C_{\mathrm{h} 2} \ln \frac{T_{0}}{T_{\text {out } 2}}+\frac{\dot{Q}_{\mathrm{e} 2}}{T_{0}}\right)}_{\dot{S}_{\mathrm{g} 2}},
\end{aligned}
$$

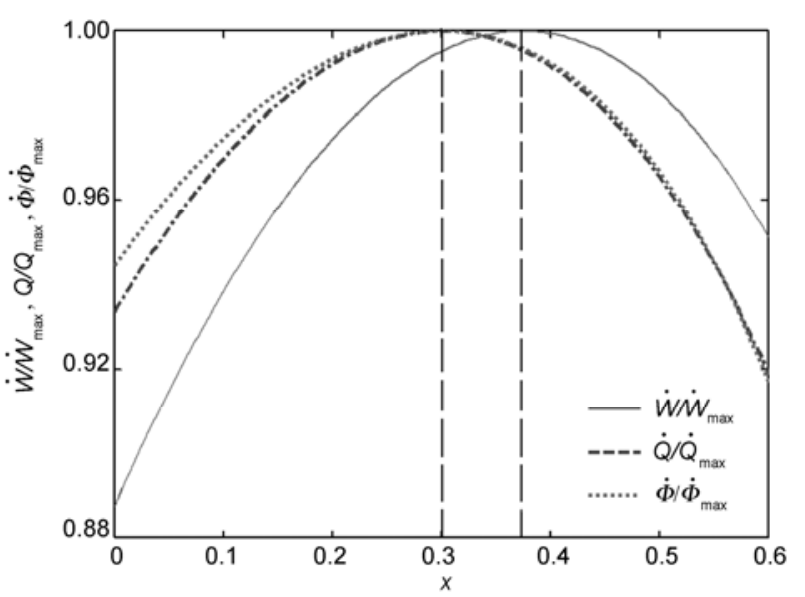

Figure 4 Total power output, heat flow rate and entransy dissipation rate versus the thermal conductance allocation ratio. 
where $T_{0}=300 \mathrm{~K}$ is the ambient temperature. Also, $\dot{Q}_{\mathrm{el}}$ and $\dot{Q}_{\mathrm{e} 2}$ are the external heat flow rates from the used streams ejected into the ambient surroundings,

$$
\begin{aligned}
& \dot{Q}_{\mathrm{e} 1}=C_{\mathrm{h} 1}\left(T_{\text {out } 1}-T_{0}\right), \\
& \dot{Q}_{\mathrm{e} 2}=C_{\mathrm{h} 2}\left(T_{\text {out } 2}-T_{0}\right) .
\end{aligned}
$$

Solving eqs. (12), (13) and (21)-(23) simultaneously provides a relation between the total entropy generation rate, $\dot{S}_{\mathrm{gh}}$, and the thermal conductance allocation ratio, $x$, plotted in Figure 5. The minimum entropy generation rate corresponds to the maximum power output $\dot{W}$ of the system at $x=0.37$, demonstrating that in optimizing a thermodynamic cycle, the minimum entropy generation rate is the appropriate quantity that should be used.

In the above case, it is assumed that the cold-end temperature equals the ambient temperature. This means an infinitely large cold-end heat exchanger is required. Since the heat exchanger size is always limited in practical applications, we have to examine the effect of finite temperature differences between cold-end and ambient temperatures on the optimal thermal conductance allocation.

Setting $T_{\mathrm{c} 1}=T_{\mathrm{c} 2}=400 \mathrm{~K}, 100 \mathrm{~K}$ above the ambient temperature, there exists one more irreversible process in the thermodynamic cycles: the heat transfer process between the cold-end and the ambient surroundings. Thus, we have the total entropy generation rates $\dot{S}_{\mathrm{gh}}$ in two hot-end heat exchangers, and $\dot{S}_{\mathrm{gc}}$ in two cold-end heat exchangers,

$$
\begin{aligned}
\dot{S}_{\mathrm{g}} & =\dot{S}_{\mathrm{gh}}+\dot{S}_{\mathrm{gc}}=\underbrace{C_{\mathrm{h}} \ln \frac{T_{0}}{T_{\mathrm{in}}}+\frac{\dot{Q}_{\mathrm{h} 1}}{T_{\mathrm{h} 1}}+\frac{\dot{Q}_{\mathrm{h} 2}}{T_{\mathrm{h} 2}}+\frac{\dot{Q}_{\mathrm{e} 1}}{T_{0}}+\frac{\dot{Q}_{\mathrm{e} 2}}{T_{0}}}_{\dot{S}_{\mathrm{gh}}} \\
& +\underbrace{\dot{Q}_{\mathrm{c} 1}\left(\frac{1}{T_{0}}-\frac{1}{T_{\mathrm{c} 1}}\right)+\dot{Q}_{\mathrm{c} 2}\left(\frac{1}{T_{0}}-\frac{1}{T_{\mathrm{c} 2}}\right)}_{\dot{S}_{\mathrm{gc}}},
\end{aligned}
$$

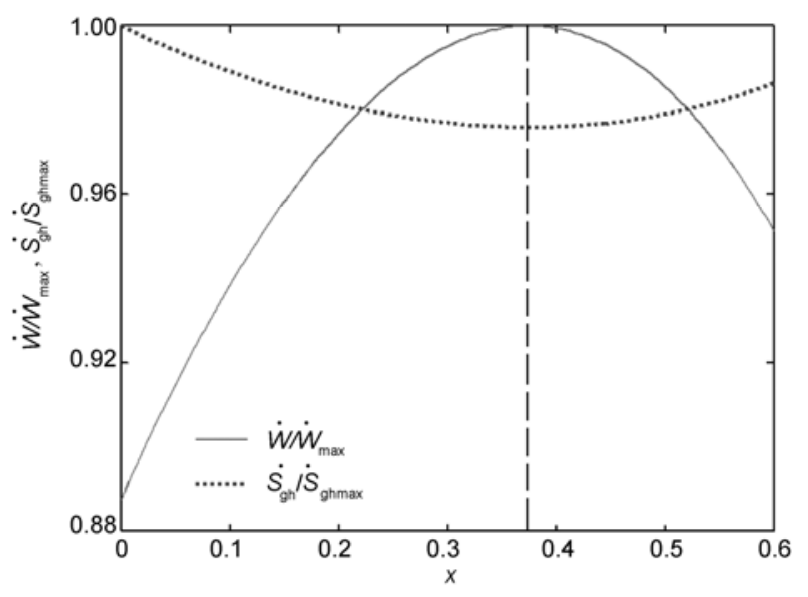

Figure 5 Total power output and entropy generation rate versus the thermal conductance allocation ratio $\left(T_{\mathrm{cl}}=T_{\mathrm{c} 2}=300 \mathrm{~K}\right)$. where $\dot{Q}_{\mathrm{c} 1}$ and $\dot{Q}_{\mathrm{c} 2}$ are the heat flow rates at the left and right cold-ends, respectively,

$$
\begin{gathered}
\dot{Q}_{\mathrm{c} 1}=Q_{\mathrm{h} 1} \frac{T_{\mathrm{c} 1}}{T_{\mathrm{h} 1}}, \\
\dot{Q}_{\mathrm{c} 2}=Q_{\mathrm{h} 2} \frac{T_{\mathrm{c} 2}}{T_{\mathrm{h} 1}} .
\end{gathered}
$$

The results for total power output, $\dot{W}$, and entropy generation rate, $\dot{S}_{\mathrm{g}}$, of the thermodynamic cycles versus the thermal conductance allocation ratio are plotted in Figure 6. When the thermal conductance allocation ratio $x=0.43$, the total entropy generation rate $\dot{S}_{\mathrm{g}}$ of the system reaches its minimum, while the total power output rate $\dot{W}$ of the cycles is at its maximum. Because the inlet fluid temperature, $T_{\mathrm{in}}$, and the heat capacity rates, $C_{\mathrm{h}}$, are given, maximal power output signifies the highest heat-work conversion efficiency. Thus, for a complete thermodynamic cycle comprising more than a single heat exchanger, minimizing entropy generation should be taken as the criterion for optimizing the thermodynamic system. Furthermore, if we ignore the external irreversibility induced by the heat transfer process from the cold-end into the ambient surroudnings, we would have $\dot{S}_{\mathrm{g}}=\dot{S}_{\mathrm{gh}}$, including only the entropy associated with the hot-end heat exchanger group as in eq. (21). Then in Figure 6, $\dot{S}_{\mathrm{g}}=\dot{S}_{\mathrm{gh}}$ turns to its minimum at $x=0.37$, which however does not correspond to the maximum of the power output $\dot{W}$.

\section{Concluding remarks}

Heat transfers can be classified into two categories according to purpose: heat-work conversion, and object heating or

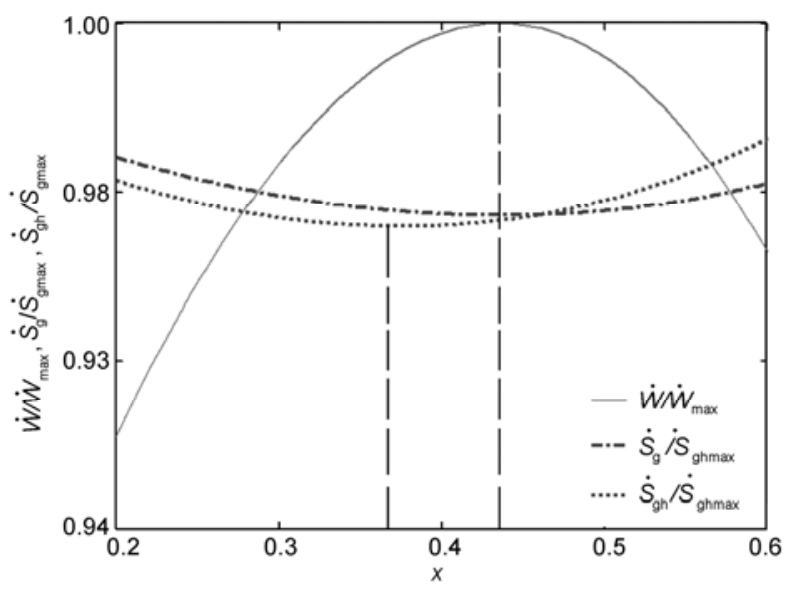

Figure 6 The total power output and different entropy generation rates versus the thermal conductance allocation ratio $\left(T_{\mathrm{cl}}=T_{\mathrm{c} 2}=400 \mathrm{~K}\right)$. 
cooling. Meanwhile, the thermal performance analyses of a heat exchanger group show that minimizing entropy generation rate is the optimization criterion for thermodynamic cycles including heat exchangers, while maximizing entransy dissipation rate is the optimization criterion of heat exchangers involved in object heating or cooling. In a thermodynamic cycle with the cold-end temperature above the ambient temperature, the method based on minimizing entropy generation rates becomes effective only when the entropy generation rates induced by both dumping the used stream into the ambient surroundings and from heat transfer processes between cold-end and ambient temperatures are taken into account.

This work was supported by the National Natural Science Foundation of China (51006060) and China Postdoctoral Science Foundation (200902080).

1 Bergles A E. Some perspectives on enhanced heat transfer2nd-generation heat transfer technology. J Heat Transf-Trans ASME, 1988, 110: 1082-1096

2 Bergles A E. Heat transfer enhancement-The maturing of second-generation heat transfer technology. Heat Transf Eng, 1997, 18: 47-55

3 Zimparov V. Energy conservation through heat transfer enhancement techniques. Int J Energy Res, 2002, 26: 675-696

4 Kreuzer H J. Nonequilibrium Thermodynamics and Its Statistical Foundations. Oxford: Clarendon Press, 1981

5 Bejan A. The concept of irreversibility in heat exchanger design: Counterflow heat exchangers for gas-to-gas applications. J Heat Transf-Trans ASME, 1977, 99: 374-380

6 Bejan A. Entropy Generation Minimization. Florida: CRC Press, 1996

7 Poulikakos D, Bejan A. Fin geometry for minimum entropy generation in forced convection. J Heat Transf-Trans ASME, 1982, 104: 616-623

8 Grazzini G, Gori F. Entropy parameters for heat exchanger design. Int J Heat Mass Transf, 1988, 31: 2547-2554

9 Sekulic D P, Campo A, Morales J C. Irreversibility phenomena associated with heat transfer and fluid friction in laminar flows through singly connected ducts. Int J Heat Mass Transf, 1997, 40: 905-914

10 Sara O N, Yapici S, Yilmaz M, et al. Second law analysis of rectangular channels with square pin-fins. Int Commun Heat Mass Transf, 2001, 28: 617-630

11 Johannessen E, Nummedal L, Kjelstrup S. Minimizing the entropy production in heat exchange. Int $\mathrm{J}$ Heat Mass Transf, 2002, 45: 2649-2654

12 Balkan F. Comparison of entropy minimization principles in heat exchange and a short-cut principle: EoTD. Int J Energy Res, 2003, 27: 1003-1014

13 Ko $\mathrm{T}$ H. Numerical analysis of entropy generation and optimal Reynolds number for developing laminar forced convection in double-sine ducts with various aspect ratios. Int J Heat Mass Transf, 2006, 49: 718-726

14 Erek A, Dincer I. An approach to entropy analysis of a latent heat storage module. Int J Therm Sci, 2008, 47: 1077-1085

15 Hesselgreaves J E. Rationalisation of second law analysis of heat exchangers. Int J Heat Mass Transf, 2000, 43: 4189-4204

16 Shah R K, Skiepko T. Entropy generation extrema and their relationship with heat exchanger effectiveness - Number of transfer unit behavior for complex flow arrangements. J Heat Transf-Trans ASME, 2004, 126: 994-1002

17 Guo Z Y, Zhu H Y, Liang X G. Entransy-A physical quantity describing heat transfer ability. Int J Heat Mass Transf, 2007, 50: 2545-2556

18 Guo Z Y, Cheng X G, Xia Z Z. Least dissipation principle of heat transport potential capacity and its application in heat conduction optimization. Chinese Sci Bull, 2003, 48: 406-410

19 Xie Z, Chen L, Sun F. Constructal optimization on T-shaped cavity based on entransy dissipation minimization. Chinese Sci Bull, 2009, 54: 4418-4427

20 Xia S, Chen L, Sun F. Entransy dissipation minimization for liquid-solid phase change processes. Sci China Technol Sci, 2010, 53: 960-968

21 Chen Q, Ren J, Meng J A. Field synergy equation for turbulent heat transfer and its application. Int J Heat Mass Transf, 2007, 50: 5334-5339

22 Chen Q, Ren J X. Generalized thermal resistance for convective heat transfer and its relation to entransy dissipation. Chinese Sci Bull, 2008, 53: 3753-3761

23 Meng J A, Liang X G, Li Z X. Field synergy optimization and enhanced heat transfer by multi-longitudinal vortexes flow in tube. Int J Heat Mass Transf, 2005, 48: 3331-3337

24 Chen Q, Wang M, Pan N, et al. Optimization principles for convective heat transfer. Energy, 2009, 34: 1199-1206

25 Wu J, Liang X G. Application of entransy dissipation extremum principle in radiative heat transfer optimization. Sci China Ser E-Technol Sci, 2008, 51: 1306-1314

26 Guo J, Cheng L, Xu M. Entransy dissipation number and its application to heat exchanger performance evaluation. Chinese Sci Bull, 2009, 54: 2708-2713

27 Liu X, Meng J, Guo Z Y. Entropy generation extremum and entransy dissipation extremum for heat exchanger optimization. Chinese Sci Bull, 2009, 54: 943-947

28 Xia S, Chen L, Sun F. Optimization for entransy dissipation minimization in heat exchanger. Chinese Sci Bull, 2009, 54: 35873595

29 Meng J A, Liang X G, Chen Z J, et al. Experimental study on convective heat transfer in alternating elliptical axis tubes. Exp Therm Fluid Sci, 2005, 29: 457-465

30 Bejan A. Entropy Generation Through Heat and Fluid Flow. New York: Wiley, 1982

Open Access This article is distributed under the terms of the Creative Commons Attribution License which permits any use, distribution, and reproduction in any medium, provided the original author(s) and source are credited. 